\title{
Guarda compartilhada: perspectivas e desafios diante da responsabilidade parental
}

\section{Shared guardianship: perspectives and challenges regarding parental responsibility}

\section{Custodia compartida: perspectivas y desafíos frente a la responsabilidad parental}

\author{
Amanda Pansard Alves* \\ Universidade Federal de Santa Maria - UFSM, Santa Maria, Rio Grande do Sul, \\ Brasil
}

\section{Dorian Mônica Arpini**}

Universidade Federal de Santa Maria - UFSM, Santa Maria, Rio Grande do Sul, Brasil

\section{Sabrina Daiana Cúnico***}

Pontifícia Universidade Católica do Rio Grande do Sul - PUC-RS, Porto Alegre, Rio Grande do Sul, Brasil

\begin{abstract}
RESUMO
A guarda compartilhada, apesar de ser compreendida como um avanço nas relações parentais pós-divórcio, ainda é recente no ordenamento jurídico brasileiro. Diante disso, este estudo buscou conhecer o relato de pais e mães a partir de suas vivências em relação a esta modalidade de guarda. Para tanto, integraram esta pesquisa três mães e dois pais que estabeleceram em acordo, realizado em uma assistência judiciária gratuita, a guarda compartilhada. Esse estudo teve caráter qualitativo, sendo executado a partir de entrevistas semidirigidas de questões abertas. Como resultados alcançados foi possível identificar que os participantes tinham entendimento claro acerca de como deve funcionar a guarda compartilhada. Contudo, foram relatadas dificuldades para o exercício desta modalidade de guarda, com destaque para a ausência paterna, a entrada de um terceiro - nova companheira do pai - e o conflito entre os ex-companheiros após o fim da relação. Diante desses impasses apresentados para o exercício da parentalidade conjunta após o término do relacionamento, entende-se necessário um acompanhamento aos pais com relação ao exercício dos cuidados parentais após a separação, para com isso auxiliar no fortalecimento da relação entre pais e filhos após o desenlace conjugal.

Palavras-chave: guarda, relações parentais, separação conjugal, família.
\end{abstract}

\section{ABSTRACT}

The shared custody, although it is understood as a breakthrough in postdivorce parental relationships, is still fresh in the Brazilian legal system. 
Given this fact, this study aimed to comprehend the report of fathers and mothers about their experiences related to children guardianship. Three mothers and two fathers who had established agreement related to shared guardianship through a free legal assistance integrated the research. Such qualitative study was carried out based on semi-directed interviews, with open-ended questions. The results evidence that the participants clearly acknowledged how the shared guardianship should work. However, difficulties concerning the exercise of such type of guardianship were reported, highlighting the absence of the father, the entrance of a third party in the relationship - the new partner of the father - and the conflict among ex-partners after the end of the relationship. In face of the challenges presented as regards the exercise of joint parenting after the end of the relationship, it is necessary to monitor the parents, as relates to parenting care, so as to help strengthening the relationships among parents and children after marital separation.

Keywords: custody, relations, marital separation, family.

\section{RESUMEN}

La custodia compartida, aunque se entiende como un gran avance en las relaciones parentales después del divorcio, es todavía reciente en el sistema jurídico brasileño. Teniendo en cuenta esto, este estudio tuvo como objetivo conocer la historia de padres y madres sobre sus experiencias en relación a la custodia de los hijos. Para ello, esta investigación integra tres madres y dos padres que establecieron un acuerdo de custodia compartida, firmado en una asistencia jurídica gratuita. El estudio tuvo carácter cualitativo, y fue ejecutado a través de entrevistas semi-estructuradas con preguntas abiertas. Con los resultados obtenidos, fue posible identificar que los participantes tenían claro entendimiento de cómo debería funcionar la custodia compartida. Sin embargo, fueron relatadas dificultades para el ejercicio de esta modalidad de custodia. Entre ellas, se destacan la ausencia paterna y la presencia de una nueva persona - nueva pareja del padre - y el conflicto entre los excompañeros después del final del matrimonio. Delante de los problemas presentados para el ejercicio de la parentalidad conjunta después del término de la relación conyugal, se entiende que es necesario el acompañamiento a los padres con respecto al ejercicio de los cuidados parentales, para auxiliar en el fortalecimiento de la relación entre padres e hijos después del desenlace matrimonial.

Palabras clave: custodia de los hijos, relaciones familiares, separación conyugal, familia.

\section{Introdução}

No Brasil, pela edição do Código Civil de 1916, o único modo de se constituir uma família era através do casamento, não havendo outra modalidade de união aceitável juridicamente. O casamento era dado como indissolúvel e a única possibilidade de término era através do desquite, que mesmo assim não dissolvia o vínculo matrimonial e impedia um novo casamento (Dias, 2015).

O Código Civil de 1916, no que se refere à guarda dos filhos, diferenciava a dissolução amigável e judicial do casamento ao estabelecer os critérios que seriam levados em consideração nas 
disputas de guarda. Enquanto na dissolução amigável era observado se existia algum acordo entre os cônjuges, na judicial era levada em conta a possível culpa de um ou de ambos pela ruptura, além do sexo e idade dos filhos, ficando estabelecida a guarda primeiramente para o cônjuge considerado inocente. Caso ambos fossem considerados culpados, a mãe ficaria com as filhas até completarem a maioridade civil e os filhos de até seis anos, sendo estes posteriormente entregues ao pai (Grisard Filho, 2009). Esse critério legal para a guarda destacava a vinculação, que existiu no direito de família nacional, entre a conjugalidade e a parentalidade, como se uma devesse influenciar a outra (Dias, 2015).

Com o estabelecimento da Lei do Divórcio em 1977, passa a ser possível que cada indivíduo se divorcie uma vez. Ainda assim, havia a diferenciação do sujeito inocente e culpado pelo rompimento do matrimônio, sendo a guarda dada ao primeiro e havendo motivos graves ficava a cargo do juiz a decisão (Brandão, 2005; Dias, 2015). Porém, no caso de serem responsabilizados ambos os cônjuges, os filhos ficariam com a mãe até atingirem a maioridade civil, salvo se esta não fosse considerada capaz de cuidá-los (Dias, 2015).

Posteriormente, com o Código Civil de 2002, é abolida a prevalência materna para a fixação da guarda nos termos da lei, sendo os interesses dos filhos o princípio a orientar o juiz na decisão. Nesse sentido, a guarda era atribuída a quem revelasse melhores condições para exercê-la (Grisard Filho, 2009; Madaleno, 2008). No entanto, como indicam as estatísticas do IBGE no ano de $2011,87,64 \%$ das guardas continuam sendo concedidas prioritariamente às mães (IBGE, 2011), demostrando que estas ainda são em maioria as detentoras da guarda após a separação conjugal ${ }^{1}$. Corroborando esses dados, a pesquisa de Alves, Cúnico, Smaniotto, Pilecco e Arpini (2014), a qual buscou compreender a concepção da paternidade através do relato de operadores do direito que atuavam em varas de família, apontou que a ideia de que a mãe é mais bem preparada para o exercício dos cuidados parentais ainda se mantém presente no discurso desses profissionais, apesar de a legislação ter ultrapassado essa concepção.

Nesse sentido, Brito (2005) revela que talvez seja por esse motivo que muitos homens relatam ter a sensação de que no momento da separação já se naturaliza o afastamento do pai em relação à prole. Ao entrevistar pais e mães separados, a autora verificou que $70 \%$ desses reconheceram que o genitor que não detém a guarda geralmente o pai - participa bem menos das decisões importantes relacionadas aos filhos. Com efeito, ainda que não se desconsidere os inúmeros pais que participam ativamente da vida dos filhos após uma dissolução, o afastamento do pai após a separação do casal pode ser considerado um desdobramento importante do contexto da família pós-separação. 
Dentre os motivos frequentemente apresentados pelos homens para justificar tal afastamento estão as dificuldades de relacionamento com a ex-companheira e/ou a família desta e o início, por parte do pai, de uma nova família (Cúnico \& Arpini, 2013). Esse fato parece demonstrar a distância entre o que ocorre após a separação do casal e o que determina a lei acerca da autoridade parental, já que é citado no atual Código Civil que, mesmo após a separação, ambos os genitores possuem este dever para com os filhos (Brasil, 2002).

Conforme assinala Brito (2005), muitos pais entendem que a justiça não trata o assunto de forma igualitária entre homens e mulheres, dificultando, dessa forma, o exercício da paternidade quando não há mais o vínculo conjugal. Além disso, muitos pais argumentam que a guarda unilateral, na qual cabe a um dos pais a guarda e ao outro o papel de fiscalizador e visitante contribui para que estes se tornem pais pouco participativos (Brito, 2005). Dessa forma, pode-se pensar que a guarda unilateral destina ao genitor não-guardião um papel secundário, privando-o de um convívio mais próximo com seu filho (Grisard Filho, 2009).

Diante dessas críticas e dos princípios da isonomia entre homens e mulheres e do melhor interesse da criança, além das transformações vivenciadas pela família contemporânea, com destaque para a maior participação e maior desejo de participar dos pais não-guardiões, estabelece-se a guarda compartilhada no Brasil. De acordo com alguns autores (Brito, 2005; Dias, 2015; Grisard Filho, 2009; Pereira, 2005) essa modalidade de guarda traria a possibilidade de reequilibrar os papéis parentais e garantir que sejam supridas as necessidades afetivas e emocionais da criança após o rompimento conjugal.

Historicamente, com relação ao exercício da guarda compartilhada, em 1980 foi aprovada a legislação que previa esta modalidade na Califórnia, EUA. A partir de então, outros estados americanos passaram a incorporar tal modalidade de guarda nos seus ordenamentos jurídicos. Na Suécia, a guarda conjunta ${ }^{2}$ encontra-se prevista há aproximadamente 30 anos. Já a França adotou em 2002 uma legislação que estabelece o exercício conjunto da parentalidade (Brito 2005; Grisard Filho 2005). No Brasil, somente em 2008 foi sancionada a lei 11.698 que institui e disciplina a guarda compartilhada.

Conforme dispõe a lei citada acima, o novo modelo de guarda prevê a responsabilização conjunta dos genitores (Brasil, 2008). Assim,

Se em nosso ordenamento jurídico o poder familiar é exercido pelo pai e pela mãe, independente de estarem juntos ou separados e diante do princípio de igualdade, não há mais necessidade de continuarmos falando em duas categorias: guardiãs e pai visitante [grifo do autor] (Pereira, 2005, p.151). 
Ainda seguindo esse entendimento, Dolto (1989/2011) assinala que ao se delegar a guarda a um dos genitores e estabelecer o papel do outro como "visitante" é implicitamente dito à criança que este outro é menos importante. Dessa forma, observa-se que o compartilhamento da guarda pode garantir o desempenho de ambos os papéis parentais - materno e paterno -, rompendo com a figura daquele pai que se faz presente apenas nos períodos de visita, assegurando assim a manutenção dos vínculos da criança com seus pais. Vínculos que são considerados fundamentais para o desenvolvimento saudável da mesma (Brito, 2005). Nesse sentido, a guarda compartilhada assinala a importância da presença de ambos os pais para a saúde da criança, buscando possibilitar aos filhos a conservação das relações que existiam antes da separação de seus pais (Brito, 2014; Grisard Filho, 2009; Ramos 2005).

Por ser recente no ordenamento jurídico brasileiro, deve-se destacar a diferença entre a guarda compartilhada e a alternada, uma vez que se têm identificado dificuldades na diferenciação entre estas duas modalidades. A guarda alternada diz respeito a uma igualdade de dias ou meses que cada um dos genitores passa com a criança, enquanto a compartilhada prevê que os filhos passem períodos com o pai e com a mãe sem que estes sejam fixados rigorosamente. Ademais, na guarda compartilhada todas as decisões importantes sobre o(s) filho(s) devem ser tomadas por ambos os pais (Grisard Filho, 2009). Em conformidade com este entendimento, Ramos (2005) afirma que compartilhar a guarda significa "partilhar em conjunto a educação e criação do filho, sob os aspectos de assistência material, moral e de convivência" (p.109). Assim, entende-se que a guarda compartilhada traz a possibilidade de amenizar a dor dos filhos que sofreram com o divórcio de seus pais e igualar os direitos e deveres de ambos os genitores, sendo uma alternativa possível para que sejam exercidas as responsabilidades parentais após o desenlace conjugal (Brito, 2014; Grisard Filho, 2009; Ramos, 2005).

Diante do exposto, vê-se a necessidade de pesquisas que abarquem esta nova modalidade de guarda, ainda pouco difundida no Brasil. Para tanto, realizou-se uma pesquisa de caráter qualitativo que teve por objetivo conhecer as vivências de pais e mães que estabeleceram, em acordo, a guarda compartilhada dos filhos.

\section{Método}

\subsection{Participantes}

Integraram esta pesquisa três mães $(M)$ e dois pais $(P)$ que em acordo, realizado em um Núcleo de Assistência Judiciária Gratuita de 
uma instituição pública de ensino superior, estabeleceram a guarda compartilhada do(s) filho(s). Os acordos se deram por meio da prática de mediação familiar, da qual participam estagiários do direito e da psicologia e uma funcionária do serviço social. Essa técnica não é substituta da via judicial, mas uma alternativa que tem por objetivo resgatar a responsabilidade das pessoas em conflito tornando a sua resolução realmente mais eficaz, uma vez que busca encontrar uma solução consensual (Dias, 2015). Nesse viés, entende-se que quando os envolvidos conseguem ocupar o lugar de responsáveis pelas decisões, a negociação tem mais chances de ser concretizada e vivenciada pelos sujeitos (Oltramari, 2009). Destaca-se que após a sua realização, os acordos são enviados para que haja a homologação judicial.

O tempo transcorrido desde o estabelecimento do acordo variou entre um ano e dois anos. No que diz respeito às idades dos participantes, essas variaram entre 32 e 47 anos. Com relação ao número de filhos, uma mãe e um pai tinham apenas um filho e o restante dos participantes tinham três filhos, no momento em que foi realizada a pesquisa.

\subsection{Instrumento}

Este estudo teve caráter qualitativo, realizado por meio de entrevistas semidirigidas. Para Turato (2003), este modelo se caracteriza por um encontro interpessoal entre entrevistador e entrevistado, em que o primeiro é o responsável pelo encontro e o segundo é um convidado a expressar suas opiniões. De acordo com o autor, existe uma troca dinâmica de direção, dada ora pelo entrevistador ora pelo entrevistado, facilitando a coleta de informações baseada no discurso livre do entrevistado através da introdução de tópicos pelo entrevistador.

\subsection{Procedimentos}

Foram realizadas entrevistas individuais, as quais ocorreram em sala adequada, nas dependências da instituição na qual as pesquisadoras estão vinculadas. Para alcançar os objetivos da pesquisa, a entrevista foi baseada nos três eixos seguintes: significados atribuídos à guarda compartilhada; atribuições e responsabilidades em relação ao cuidado com o(s) filho(s) e experiência com relação à guarda compartilhada. Impende destacar que antes do início da entrevista, os participantes foram esclarecidos sobre os objetivos da pesquisa, sendo também entregue a eles o Termo de Consentimento Livre e Esclarecido (TCLE), momento em que ficaram cientes do compromisso de sigilo sobre suas identidades por parte das pesquisadoras. Destaca-se que o estudo está respaldado nas Diretrizes e Normas Regulamentadoras 
de Pesquisa envolvendo Seres Humanos (Resolução 466/12 do Conselho Nacional de Saúde) e na Resolução no 016/2000 do Conselho Federal de Psicologia, sendo aprovada a realização da pesquisa pelo Comitê de Ética de uma universidade pública de ensino superior, sob o número 03926312.4.0000.5346.

\subsection{Análise dos dados}

Depois de realizada a transcrição na íntegra das cinco entrevistas, as quais haviam sido gravadas em áudio, foi realizada a análise dos dados obtidos. A análise foi qualitativa, sendo utilizada a análise de conteúdo proposta por Bardin (2011). Foi feita a leitura e a análise individual de cada entrevista transcrita, momento em que foram identificados os aspectos referentes a temática proposta no estudo de cada uma delas. Após isso, identificaram-se aspectos comuns presentes nas falas dos entrevistados e realizou-se o agrupamento destes temas em tópicos, que foram posteriormente elencados em categorias a fim de promover o melhor entendimento sobre os dados obtidos. A partir da obtenção das categorias foi possível relacionar o material das entrevistas com outros estudos que tratavam sobre 0 assunto em tela.

\section{Resultados e discussão}

Os resultados deste estudo serão apresentados em três categorias, quais sejam: 1. Entendimento sobre a guarda compartilhada; 2. A guarda compartilhada no cotidiano familiar: dividindo as responsabilidades; 3. Obstáculos para o exercício da guarda compartilhada: dificuldades vivenciadas. A primeira diz respeito ao entendimento que pais e mães possuem acerca da guarda compartilhada e como ela deve funcionar. A segunda refere-se à experiência positiva que relataram. Já a terceira categoria abrange as dificuldades enfrentadas por estes pais com a guarda compartilhada.

\subsection{Entendimentos sobre a guarda compartilhada}

Conforme já exposto, segundo definição legal, a guarda compartilhada é a "responsabilização conjunta e o exercício de direitos e deveres do pai e da mãe que não vivam sob o mesmo teto, concernentes ao poder familiar dos filhos comuns" ( $\$ 1$ o, art. 1.583, Código Civil Brasileiro de 2002, alterado pela Lei $\left.n^{\circ} 11.698 / 2008\right)$. A fala de pais e mães acerca do entendimento que eles têm sobre esta modalidade de guarda apresenta-se em conformidade com o que a doutrina jurídica preconiza, conforme as falas a seguir: 
Eu acho que seria os dois agirem em comum acordo em relação ao filho né?!(...) pra ver as decisões a serem tomadas com o filho. (...) o pai também pode tá com ela quando ele quer, pegar ela pra ver, pra ficar com ele, ter as decisões mesmo em relação mesmo a ela, estudo, tudo, eu acho que seria isso. (M1)

(...) acho que pra mim é (...) assim ter mais acesso a ele, poder tá mais junto com ele, acompanhar a criação, (...) eu poder acompanhar o dia-a-dia, o que que tá acontecendo, o que que não tá.(...) eu acho que seria isso né, a participação dos dois. (P2)

De acordo com Grisard Filho (2009), a guarda compartilhada busca reequilibrar os papéis parentais após a separação, atendendo o interesse da criança ou adolescente já que busca manter os dois pais envolvidos na sua criação, sendo, dessa forma, um meio para manter os vínculos entre pais e filhos após a ruptura conjugal. Além disso, este dispositivo de guarda tem por objetivo a responsabilização do genitor que não habita com o filho, na tentativa de evitar que a separação conjugal ocasione uma separação parental (Brito, 2014; Brito \& Peçanha, 2006). Neste sentido, uma mãe refere-se à guarda compartilhada como uma divisão de "deveres" e "compromissos".

(...) se precisar tá os dois juntos, conviver assim, pai e mãe passam por tudo que é barreira, se tiver que participar de alguma coisa junto, vamo junto, eu penso assim. (...) tem os deveres que é tanto de um quanto do outro, os compromissos. (M3)

Além dessa responsabilização conjunta dos pais, também é importante para a criança que ela conviva com ambos os genitores para que construa sua própria imagem de cada um deles, sem interferência de um dos pais (Silva, 2005). Essa representação, de acordo com Silva, está relacionada à qualidade do convívio no período em que os pais permanecem com a criança. Apesar disso, uma das mães entrevistadas quando questionada acerca de seu entendimento sobre esta modalidade de guarda revela certa distorção a respeito do que considera ser a guarda compartilhada:

um final de semana meu, um final de semana dele (...) acho que é participar das coisas do filho, assim, ir lá de vez em quando, mesmo que ela [referindo-se à filha] não fosse pra lá, fosse saber se ela precisava de alguma coisa, como é que tava, ou não né. (M2) 
A partir do recorte apresentado, pode-se perceber que haveria, na visão da participante, pouca clareza acerca do que é definido por guarda compartilhada e o que seria a guarda alternada. Contudo, como já mencionado, a guarda alternada é diferente da compartilhada. Na primeira costuma-se dividir igualmente o tempo em que cada um dos pais permanecerá com a criança, ou seja, em certo período de tempo pré-estabelecido cada um dos pais deterá a guarda do filho de forma unilateral. $\mathrm{Na}$ guarda compartilhada, diferentemente, os pais possuem esta guarda permanentemente em conjunto, mesmo a criança residindo com um deles (Brito, 2005; Pereira, 2011).

Pode-se pensar que talvez esta mãe não tenha recebido informações claras sobre a guarda compartilhada, no momento da realização do acordo na assistência judiciária em questão. Com relação a isso, 0 atual Código Civil brasileiro, em seu artigo 1.584, parágrafo 1으, indica que em audiência o juiz deve informar aos pais o significado, a importância e os direitos e deveres dos genitores que optem por esta modalidade. Embora o acordo não tenha sido realizado na presença de um juiz, esse aspecto parece se mostrar relevante uma vez que ainda se encontra presente certa concepção tradicional, por parte de operadores do direito, em relação aos papéis parentais quando há dissolução conjugal (Alves, et al., 2014).

Diante disso, a informação sobre todas as modalidades de guarda, em especial a guarda compartilhada, é fator imprescindível para que o ex-casal possa se sentir instrumentalizado para pensar e decidir sobre o exercício parental após o divórcio. Contudo, é importante destacar que, mesmo naquelas situações em que possa haver certo equívoco na vivência, ou no entendimento acerca da guarda compartilhada, ainda assim, parece ser importante que ela seja compreendida como uma forma de garantir o exercício parental de ambos.

\subsection{A guarda compartilhada no cotidiano familiar: dividindo as responsabilidades}

Foi possível verificar algumas situações que apontaram para uma experiência positiva com relação ao compartilhamento da guarda dos filhos. Além disso, visualizou-se uma correspondência entre o entendimento e a vivência destes pais com relação à guarda conjunta dos filhos, conforme a fala a seguir:

(...) ela deixa bem aberto pra mim fazer as visitas, o dia, a hora que eu quiser, assim sabe?! Até a gente mora perto um do outro, (...) então ele sai do colégio, vai lá pra casa, (...) tem dias da semana que ela estuda né, aí ele fica lá até a hora dela chegar da aula. (...) então ficou pra mim visitar a hora que eu 
quiser, como eu quiser, pegar ele dias de férias essas coisas assim não tem problema. (P2)

Conforme a fala do pai (P2), parece existir uma flexibilidade das visitas, o que estaria acarretando em um maior convívio com seu filho. Embora ainda pareça haver um predomínio da mãe, no que diz respeito à tomada de decisões, quando o participante relata que "ela deixa". Esse convívio diário, proporcionado pela livre visitação, possibilita a ambos os pais a manutenção dos vínculos e, consequentemente, uma maior responsabilização com a educação e o cuidado da prole (Brito, 2005).

De acordo com Grzybowski e Wagner (2010), mesmo que aquele pai residente se envolva mais em situações práticas da vida do filho, isso não exclui a possibilidade de uma coparentalidade saudável após a separação, ou seja, aquela na qual existe cooperação, planejamento e divisão de tarefas. Assim, o genitor que reside com a criança não é unicamente o detentor dos deveres para com os filhos, estando dessa forma em conformidade com o que o Código Civil, em seu artigo 1579, menciona acerca dos deveres dos pais após o divórcio. O mesmo participante afirma como se dá a tomada de decisões relacionadas ao filho:

(...) tudo o que eu vou fazer em relação a ele [referindo-se ao filho] a gente conversa eu e ela [ex-companheira] pra entrar num acordo né, pra ver se, e também tem outra coisa, a gente conversa muito com ele também, pra ver se ele aceita. (P2)

É possível perceber, através da fala desse pai, que existe uma boa relação entre ele e sua ex-companheira, o que faz possível o estabelecimento do diálogo para "entrar num acordo". No entanto, uma das participantes (M3), durante a entrevista relata que ainda que seu relacionamento com o ex-companheiro não seja bom, ambos têm conseguido dividir os deveres com relação ao filho.

(...) no colégio essas coisa, é o pai dele que tá indo, mas eu tô por dentro, sei de tudo (...) e o pai dele tá ali, eu sei que tá presente, eu tenho informações tudo direitinho, (...). Tão sempre junto, se ele precisar tão no telefone, na hora que precisar o pai dele vai, ele tá bem pontual nesse lado (...) eu tô sabendo de tudo o que tá acontecendo. (M3)

De acordo com Pereira (2011), os ex-cônjuges que se entendem e conseguem estabelecer um diálogo, naturalmente compartilham os deveres e participam do cotidiano dos filhos. Assim, conforme o autor, a Lei $n^{\circ} 11.698 / 2008$ é destinada àqueles pais que possuem um conflito entre si, não conseguindo se comunicar e estabelecer a 
divisão de responsabilidades, o que parece ser o caso da participante M3. Nesse sentido, quando o ex-casal não possui um bom relacionamento, a guarda conjunta dos filhos poderia ser indicada como forma de evitar que se instale a síndrome da alienação parental na qual um dos genitores exerce interferência na criança ou adolescente induzindo-o contra o outro genitor, na tentativa de romper os vínculos com este (Pinho, 2011).

Em contraposição, de acordo com Madaleno (2008), o estabelecimento da guarda compartilhada é viável quando o relacionamento dos pais é amigável, havendo o mínimo de entendimento para que as decisões sobre os filhos sejam tomadas em conjunto, evitando que eles sejam atingidos pelos conflitos decorrentes da separação e, consequentemente, do poder parental. Brito (2014) assinala que essa falta de aproximação e cooperação entre os pais tem sido o principal argumento para o não estabelecimento dessa modalidade de guarda. Conforme a mesma autora, esse critério estaria relacionando a conjugalidade à parentalidade, aspecto já ultrapassado quando observamos nossa legislação e que deveria ser superado pelo ex-casal durante o processo de separação em busca da preservação dessa última.

\subsection{Obstáculos para o exercício da guarda compartilhada: dificuldades vivenciadas}

\subsection{1. "Ele não compartilha a guarda comigo": ausência paterna}

Alguns estudos apontam que pode haver um distanciamento dos pais após a separação, quando estes não residirem mais com os filhos (Cúnico \& Arpini, 2013; Dantas, Jablonski, \& Féres-Carneiro, 2004). A guarda compartilhada surge nesse contexto como uma possibilidade de manter esses vínculos mesmo após a separação, como já mencionado anteriormente. No entanto, mesmo com o acordo de compartilhamento da guarda homologado judicialmente, duas mães afirmam que seus ex-companheiros não convivem mais com os filhos.

(...) antes de eu fazer a separação e tudo, ele até pegava ela, levava ela pra casa, ficava uns dois, três dias junto com ela e tudo. Mas, depois... ele não pega muito ela, ele não vê mais ela, muito difícil o dia que ele vê. (...) ele sempre começou a dar desculpa assim, que trabalhava muito sabe?! Que não podia. (...) ele ficou seis meses sem ver ela. Ano passado era aniversário dela ele nem ligar pra ela, ele não ligou. (M1)

(...) ele teria um dia para ir buscar, a hora para entregar. Ficou decidido que nas férias ele levaria a guria pra lá, só que ele nunca cumpriu isso, ele nunca fez essa parte assim, pra dizer a 
verdade a última vez que ela foi pra lá foi em junho do ano passado. (...) ele não compartilha a guarda comigo. (M2)

É possível identificar, de acordo com os recortes anteriores, uma mudança no envolvimento e cuidado do pai com os filhos após a consolidação da separação. Em pesquisa empreendida por Cúnico e Arpini (2013), a qual teve por objetivo conhecer os motivos que levam os pais a se afastarem dos filhos após a separação, foi identificado pelos participantes do estudo como um empecilho para o exercício da paternidade a "falta de tempo" e o "excesso de trabalho", situação semelhante à trazida pela participante M1.

Neste viés, Padilha (2008) e Alves et al. (2014) pontuam que ainda é culturalmente aceita a ideia do pai como o provedor da família e a mãe como a cuidadora do lar e dos filhos. De acordo com Dantas et al. (2004), a insatisfação das mães após a separação está relacionada com a falta de contato do pai com os filhos, o que implica em um desgaste por parte dela, já que fica responsável na totalidade pelo cuidado para com a prole.

Nesta direção, uma das mães participantes (M1) narra ter tentado diversas vezes fazer com que o pai de sua filha fosse mais presente e participasse da vida dela. No entanto, se mostra cansada e relata pretender mudar a modalidade de guarda.

(...) no caso é guarda compartilhada, mas quem assume toda a responsabilidade sou eu. (...) então como ele não comparece e eu acabo não falando mais pra ele, eu não tô agindo de acordo com a lei né, não tô perguntando pra ele, eu tô fazendo o que eu acho, que a responsabilidade dela é minha. Então é complicado mesmo, porque eu não sei, não sei o que fazer, eu pretendo até tirar a guarda compartilhada. (M1)

Através desta fala, pode-se inferir que a lei não assegura que sejam cumpridas as suas determinações, neste caso, o exercício conjunto da guarda. Mesmo estabelecido e homologado o acordo referente à guarda compartilhada da filha, o pai acaba afastando-se dela após a separação, fazendo com que todas as obrigações recaiam sobre a mãe. Nesta perspectiva, Pereira (2011) assinala que somente através das leis jurídicas não há como assegurar que sejam exercidos conjuntamente os cuidados parentais. Em concordância com o exposto, Alexandre e Vieira (2009), observaram que nem sempre a modalidade da guarda compartilhada assegura a manutenção dos papéis parentais ou é suficiente para garanti-los. Entretanto, também podemos pensar que, se essas dificuldades são vivenciadas quando a guarda conjunta é estabelecida, as mesmas se encontram presentes na guarda unilateral. Porém, neste último caso, há menos espaço 
para o não guardião, já que ele possui apenas o papel de fiscalizador e visitante.

\subsection{2. "A gente não se dá": dificuldade de relacionamento com o ex-cônjuge}

Outra situação identificada, através dos relatos dos participantes, como um empecilho para o exercício da guarda compartilhada, foram os problemas e conflitos com o ex-companheiro. Nesse contexto, Grzybowski e Wagner (2010) assinalam que é possível que os fatores presentes na época da separação influenciem no exercício coparental posterior. Além disso, o relacionamento pós-divórcio dos pais poderá contribuir ou não - dependendo da forma como esses resolvem seus conflitos - para o ajustamento saudável da criança ante esta nova configuração em que a família apresenta (Costa \& Dias, 2012; Dantas et. al, 2004). É possível notar, através da fala da participante, que a ruptura conjugal deflagrou o afastamento dos pais: “(...) eu não procuro, nem ele me procura, porque a gente não se dá sabe?!Ele não aceita [referindo-se à separação], ele não aceitou até agora né." (M2).

Observa-se que ainda hoje permeia no imaginário social e é partilhado por ex-casais a vinculação entre ser bom pai/mãe e bom cônjuge, entendimento já ultrapassado pela legislação nacional quando não define mais a guarda através da noção de culpa pelo fim do casamento (Brito \& Peçanha, 2006). Nesse sentido, a fala do participante (P1) possibilita visualizar a interferência no convívio deste pai com seus filhos, gerada possivelmente pelas dificuldades na condução dos conflitos resultantes da separação.

Existe, existe, existe [referindo-se a dificuldade para exercer a guarda compartilhada] mais por causa dela que não quer, que não tá deixando. Eu acho que ela não quer, não deixa, pra depois dizer que eu que não quero procura eles, que eu não procuro eles. (...) e ela própria mesmo me proibiu de entrar dentro do pátio. (P1)

Diante disso, Féres-Carneiro (1998) e Pereira (2011) assinalam que os pais em processo de separação deveriam deixar os filhos fora do conflito conjugal. É necessário que haja uma diferenciação entre o casal conjugal e a dupla parental, visto que é o primeiro que passa a não existir após a dissolução conjugal, já o segundo deveria permanecer com seus deveres perante a prole, conforme já afirmado (Dolto 1989/2011; Féres-Carneiro, 1998; Pereira, 2011).

No entanto, essa distinção nem sempre é facilmente vivenciada, uma vez que, conforme aponta Féres-Carneiro (1998), os pais muitas vezes se sentem frustrados diante do fim do relacionamento podendo 
dificultar a manutenção da convivência entre os filhos e o ex-cônjuge. Será preciso que o ex-casal compreenda que a separação exige uma reorganização, nas quais ambos terão que redefinir seu papel para além daquele casamento que se rompeu. Essa administração é fundamental, especialmente para os filhos, em função da manutenção desse vínculo (Guimarães \& Amaral, 2008).

Nesse sentido, foi aprovada recentemente a lei 13.058 que visa o estabelecimento da guarda compartilhada mesmo nos casos em que não há consenso por parte do ex-casal. Assim, a falta de um bom relacionamento entre os pais não deverá ser considerada um motivo suficiente para que o juiz não estabeleça essa modalidade de guarda nos processos de separação judicial, tornando-se a primeira escolha para todos.

\subsection{3. "Ela podia entender um pouco mais o meu lado": empecilhos impostos pela parceira atual}

Ao se estabelecer um novo relacionamento após a separação é inevitável que esta segunda família carregue marcas deixadas pela relação anterior, especialmente quando existem filhos em comum. Por estar sendo um momento de transformação, é esperado que ocorram dificuldades na ocupação destes complexos novos papéis parentais, em que o relacionamento progenitor-filhos antecede 0 relacionamento do casal (Brun, 2010; McGoldrick \& Carter, 1995).

Até porque ela tem um filho também, e eu acho que ela podia entender um pouco mais o meu lado, sabe? Muitas vezes eu deixo de fazer algumas programações com meu filho assim, pra tá junto com o filho dela, entendeu?! E ela não sabe entender isso. (...) Eu já tive outro relacionamento antes dela, de sete meses, aconteceu a mesma coisa, ela começou a ter ciúmes do meu filho e eu disse 'entre tu e o meu filho eu vou escolheu o meu filho', e essa eu acho que tá indo pro mesmo lado. Sabe? Entre ela e o meu filho, eu vou escolher o meu filho. (P2)

O recorte exposto anteriormente permite refletir sobre os problemas que podem se apresentar quando existe uma tentativa de recriar a família nuclear ainda intacta, não estabelecendo estes novos papéis (McGoldrick \& Carter, 1995). Como exemplo dessa tentativa de reprodução, observa-se que, para alguns pais, esse novo relacionamento pode funcionar como uma anulação da experiência familiar anterior, podendo o pai se distanciar dos filhos com os quais não reside (Corso \& Corso, 2011). Por outro lado, é possível que existam situações em que um novo membro na família poderá influenciar de maneira positiva na manutenção da parentalidade (Alves, 2015). 
Compreende-se, a partir da reflexão de diversos autores (Falcke, 2002; Féres-Carneiro, 1998; McGoldrick \& Carter; 1995; Soares, 2011), que tentar anular a experiência familiar anterior, tomando este arranjo familiar como uma reedição da família nuclear estará impossibilitando o estabelecimento de um novo papel por parte da(o) companheira(o) do(a) pai/mãe. Faz-se necessário compreender esta nova configuração familiar a partir de suas características singulares, realizando uma reorganização frente a esta.

Parece importante salientar que, no entanto, o participante (P2) visualiza sua nova companheira como alguém que está trazendo dificuldades para o convívio dele com seu filho. Porém, mesmo tendo esta percepção, em alguns momentos relata deixar de realizar atividades com seu filho para estar junto ao filho de sua namorada, conforme afirmou no trecho anterior. Nesse sentido, o recasamento, de acordo com Costa e Dias (2012), pode trazer conflitos ao progenitor que não reside com os filhos advindos do relacionamento anterior, no que diz respeito a manter o comprometimento com esses, levando a um distanciamento que muitas vezes é gradual, mas que pode culminar com a ausência da relação parental de cuidado, ficando, muitas vezes, apenas a obrigação formal do pagamento da pensão.

\section{Considerações finais}

A partir das considerações tecidas na discussão dos resultados deste estudo, observou-se que alguns dos participantes da pesquisa apresentaram um entendimento sobre a guarda compartilhada em conformidade com a redação da lei. Porém, pôde-se constatar que, mesmo havendo essa compreensão a respeito de como deve funcionar esta modalidade de guarda, existiram empecilhos para o exercício cotidiano da mesma, como: o afastamento do genitor que não reside com os filhos; a dificuldade de relação entre os genitores após a separação e a entrada de um terceiro membro na família.

Foi possível ressaltar também que, mesmo estando estabelecido judicialmente o dever de ambos os pais compartilharem os cuidados para com os filhos, nem sempre tal exercício pôde ser vivenciado. Esta situação aponta para a presença de dificuldades que implicaram no afastamento do pai, mantendo-se, em todos os casos, a mãe como a principal figura na manutenção dos cuidados parentais. Isto parece refletir uma perspectiva histórica de que a mãe é "naturalmente" responsável e mais capacitada para o exercício desta função, sendo recentes os estudos que envolvem os cuidados parentais por parte do pai (Gomes \& Resende, 2004; Silva \& Piccinini, 2007; Staudt \& Wagner, 2008). Nesse sentido, há ainda um caminho 
a percorrer em direção ao fortalecimento da relação paterno-filial que vá para além das obrigações pecuniárias.

Pode-se pensar que parte das dificuldades apresentadas pelos pais neste estudo em relação a vivência da guarda compartilhada possam também estar relacionadas ao período de adaptação à separação conjugal que pode variar em cada contexto familiar. Além disso, é importante considerar que as dificuldades apresentadas pelos participantes em relação à guarda compartilhada talvez possam se fazer presentes em outras modalidades de guarda. No entanto, como o foco deste estudo foi a guarda compartilhada as questões aqui colocadas dizem respeito apenas a essa vivência.

Destaca-se que a lei que prevê a guarda compartilhada é, sem dúvida, um grande avanço no cenário das relações familiares, contudo não se pode delegar somente ao poder judiciário a tarefa de manter os vínculos afetivos entre pais e filhos. Dessa forma, a partir deste estudo, ressalta-se a importância da construção de espaços que promovam o diálogo acerca das relações familiares na separação, possibilitando que os conflitos conjugais não tenham tanta repercussão no exercício da parentalidade. Também, destaca-se a importância de oferecer aos pais um acompanhamento após o estabelecimento dos acordos, sendo esse um espaço voltado ao diálogo e enfrentamento das dificuldades que poderão surgir, buscando, assim, o melhor interesse da criança e a promoção de saúde no contexto da família.

Por fim, como limitações deste estudo aponta-se o fato de o mesmo ter sido realizado em apenas uma instituição e com participantes que haviam estabelecido a guarda compartilhada em um acordo, ou seja, de modo consensual. Diante disso, como sugestão para estudos futuros, indica-se a realização de pesquisas que abordem essa temática a partir da lei 13.058, a qual determina a guarda compartilhada como prioritária.

\section{Referências}

Alexandre, D. T., \& Vieira, M. L. (2009). A influência da guarda exclusiva e compartilhada no relacionamento entre pais e filhos. Psicologia em pesquisa, 3(2), 52-65.

Alves, A. P. (2015). Quem é a nova companheira do pai? A experiência das "madrastas contemporâneas" em famílias recasadas. (Dissertação de mestrado). Universidade Federal de Santa Maria, Santa Maria.

Alves, A. P., Cúnico, S. D., Smaniotto, A. C., Pilecco, M. B., \& Arpini, D. M. (2014). O mito do amor materno e sua implicação nas decisões judiciais. In M. D. Arpini \& S. D. Cúnico (Orgs.), Novos 
olhares sobre a família: aspectos psicológicos, sociais e jurídicos (pp. 55-70). Curitiba: CRV.

Bardin, L. (2011). Análise de conteúdo (ed. rev. e amp.). Lisboa: Edições 70.

Brasil. (2002). Código Civil Brasileiro. ( $13^{\circ}$ ed.). São Paulo: Saraiva.

Brandão, E. P. (2005) A interlocução com o direito à luz das práticas psicológicas em varas de família. In Brandão, E. P.; Gonçalves, H. S. (Orgs.), Psicologia Jurídica no Brasil. 2 ed. (51-97). Rio de Janeiro: NAU Ed.

Brito, L. M. T. (2005). Guarda Compartilhada: um passaporte para a convivência familiar. In APASE - Associação de pais e mães separados (Orgs.), Guarda Compartilhada: aspectos psicológicos e jurídicos (pp. 53-69). Porto Alegre: Equilíbrio.

Brito, L. M. T. (2014). Rupturas familiares: olhares da psicologia jurídica. In M. D. Arpini \& S. D. Cúnico (Orgs.), Novos olhares sobre a família: aspectos psicológicos, sociais e jurídicos (pp. 55-70). Curitiba: CRV.

Brito, L. M. T., \& Peçanha, R. F. (2006). Separação conjugal e relações familiares: debates recentes. Interações 12(22), 87104.

Conselho Federal de Psicologia. (2000). Resolução CFP no 016/2000 de 20 de dezembro de 2000. Dispõe sobre a realização de Pesquisa em Psicologia com Seres Humanos. Brasília/DF.

Conselho Nacional De Saúde (2012). Resolução do Conselho Nacional de Saúde 466/12. Recuperado em 12 de junho de 2013 de <http://conselho.saude.gov.br/resolucoes/2012/Reso466.pdf>

Corso, D. L., \& Corso, M. (2011). A psicanálise na Terra do Nunca: ensaios sobre a fantasia. Porto Alegre: Penso.

Costa, J. M., \& Dias, C. M. S. D. (2012). Famílias recasadas: mudanças, desafios e potencialidades. Psicologia: teoria e prática, 14(3), 72-87.

Cúnico, S. D., \& Arpini, D. M. (2013). O afastamento paterno após o fim do relacionamento amoroso: um estudo qualitativo. Interação em Psicologia, 17(1), 97-106. doi: http://dx.doi. org/10.5380\%2Fpsi.v17i1.27560

Dantas, C., Jablonski, B., \& Feres-Carneiro, T. (2004). Paternidade: considerações sobre a relação pais-filhos após a separação conjugal. Paidéia, 14, 347-357. Recuperado de http: //www.scielo.br/scielo. php?script=sci_arttext\&pid=S0103$863 \times 2004000300010 \&$ Ing $=$ en\&tIng $=$ pt. $\quad 10.1590 /$ S0103$863 \times 2004000300010$

Dias, M. B. (2015). Manual de Direito das Famílias. (10 ${ }^{a}$ ed. rev., atual. e ampl.). São Paulo: Revista dos Tribunais.

Dolto, F. (2011). Quando os pais se separam (Ribeiro, V. Trad.). Rio de Janeiro: Zahar. (Original publicado em 1989) 
Falcke, D. (2002). Mães e madrastas - Quem são estas personagens? In Wagner, A. (Coord.) Família em Cena: tramas, dramas e transformações. (pp. 77-92). Petrópolis: Vozes.

Féres-Carneiro, T. (1998). Casamento contemporâneo: o difícil convívio da individualidade com a conjugalidade. Psicologia Reflexão e Crítica, 11, 379-394. Recuperado de http: //www.scielo.br/scielo.php?script=sci_arttext\&pid=S010279721998000200014\&lng=pt\&tlng=pt. $\quad$ 10.1590/S010279721998000200014

Gomes, A. J. S., \& Resende, V. R. (2004). O pai presente: o desvelar da paternidade em uma família contemporânea. Psicologia: Teoria e Pesquisa, 20(2), 119-125.

Grisard Filho, W. (2009). Guarda Compartilhada: um novo modelo de responsabilidade parental ( $4^{\circ}$ ed. rev., atual. e ampl.) São Paulo: Editora Revista dos Tribunais.

Grzybowski, L. S., \& Wagner, A. (2010). Casa do pai, casa da mãe: a coparentalidade após o divórcio. Psicologia: teoria e pesquisa, 26(1), 77-87. Recuperado de http://www.scielo.br/scielo.php?script=sci_arttext\&pid=S0102$37722010000100010 \&$ Ing $=$ en\&tIng $=$ pt. 37722010000100010

Guimarães, N. V. O., \& Amaral, A. C. (2008) Famílias com filhos de casamentos anteriores. In L. C. Osorio \& M. E. P. Valle (Orgs.), Manual de Terapia Familiar (pp. 271-285). São Paulo: Artmed, 2008.

Instituto Brasileiro de Geografia e Estatística. (2011). Divórcio responsáveis pela guarda de filhos menores. Recuperado em 11 de outubro, 2014 de http://www.ibge.gov.br

Lei no 11.698, de 13 de junho de 2008. Lei sobre guarda compartilhada. Brasília, DF: Presidência da República.

Lei n. 13.058, de 22 de dezembro de 2014. Altera os arts. 1.583, $1.584,1.585$ e 1.634 da Lei $n^{0} 10.406$, de 10 de janeiro de 2002 (Código Civil), para estabelecer o significado da expressão "guarda compartilhada" e dispor sobre sua aplicação. Diário Oficial da União, Brasília, DF.

Madaleno, R. (2008). Curso de direito de família. (2a ed.) Rio de Janeiro: Forense. (Original publicado em 2008).

McGoldrick, M., \& Carter, B. (1995). Construindo uma família recasada. In B. Carter \& M. McGoldrick (Orgs.), As mudanças do ciclo de vida familiar: uma estrutura para a terapia de família (pp. 344-369). Porto Alegre: Artes Médicas.

Oltramari, L. C. (2009). Mediação familiar nos contextos de conjugalidade. In S. L. R. Rovinski \& R. M. Cruz (Orgs.), Psicologia jurídica: perspectivas teóricas e processos de intervenção (pp. 247-258). São Paulo: Vetor. 
Pereira, R. C. (2005). Princípios norteadores para o direito de família. Belo Horizonte: Del Rey.

Pereira, R. C. (2011). Divórcio: teoria e prática. (3a ed.) Rio de Janeiro: GZ Ed. (Original publicado em 2010).

Pinho, A. C. (2011). A Alienação Parental e a guarda compartilhada como forma de prevenção. Revista USCS, X(21), 135-152.

Ramos, P. P. C. (2005). A moderna visão da autoridade parental. In APASE - Associação de pais e mães separados (Orgs.), Guarda Compartilhada: aspectos psicológicos e jurídicos. (pp. 97-121) Porto Alegre: Equilíbrio.

Silva, E. L. (2005). Guarda de filhos: aspectos psicológicos. In APASE - Associação de pais e mães separados (Orgs.). Guarda Compartilhada: aspectos psicológicos e jurídicos. (pp. 13-32) Porto Alegre: Equilíbrio.

Silva, M. R., \& Piccinini, C. A. (2007). Sentimentos sobre a paternidade e o envolvimento paterno: um estudo qualitativo. Estudos de Psicologia, Campinas, 24(4), 561-573.

Soares, L. C. E. C (2011). Reflexión. Ser padre, ser madre, ser padrasto, ser madrasta: aspectos psicológicos y jurídicos. Anuário de psicologia jurídica, 21, 125-130.

Staudt, A. C. P., \& Wagner, A. (2008). Paternidade em tempos de mudança. Psicologia: Teoria e Prática, 10(1), 174-185.

Turato, E. R. (2003). Tratado de metodologia da pesquisa clínicoqualitativa. Petrópolis: Vozes.

\section{Endereço para correspondência \\ Amanda Pansard Alves}

Universidade Federal de Santa Maria

Rua Guilherme João Fabrin, 402, Nossa Sra de Lourdes, CEP 97050-280, Santa Maria - RS, Brasil

Endereço eletrônico: amanda.pansard@hotmail.com

\section{Dorian Mônica Arpini}

Universidade Federal de Santa Maria

Campus Universitário

Avenida Roraima, CCSH, Prédio 74b sala 3208, CEP 97105-900, Santa Maria - RS, Brasil

Endereço eletrônico: monica.arpini@gmail.com

\section{Sabrina Daiana Cúnico}

Pontifícia Universidade Católica do Rio Grande do Sul

Rua Chile, 461 apto 503, Jardim Botânico, CEP 90670-140, Porto Alegre - RS, Brasil

Endereço eletrônico: sabrinacunico@yahoo.com.br

Recebido em: 28/10/2014

Reformulado em: 20/08/2015

Aceito para publicação em: 24/08/2015

\section{Notas}

* Mestre em psicologia pela Universidade Federal de Santa Maria. 
** Prof. Dr ${ }^{a}$ pelo Departamento de Psicologia da Universidade Federal de Santa Maria.

*** Doutoranda em Psicologia pela Pontifícia Universidade Católica do Rio Grande do Sul.

1 Nesse estudo não se fez diferenciação entre os termos separação conjugal e divórcio, tendo sido ambos utilizados como sinônimos.

2 As expressões guarda compartilhada e guarda conjunta serão utilizadas como sinônimos. 